in 1989. On the positive side, fluoridation continues to provide substantial benefits for the dental health of six million people, many of them living in the west midlands and the north east of England.

The arguments for extending fluoridation are not as overwhelming as they were in 1956. The prevalence of dental caries has fallen in both fluoridated and non-fluoridated districts, ${ }^{5}$ and the costs of fluoridation plant designed to meet modern operating standards are considerable. ${ }^{6}$ It is sensible therefore that the health departments should give priority for new schemes to areas such as the north west of England ${ }^{7}$ and the west of Scotland where the prevalence of dental caries remains high and where large water treatment works allow for economies of scale.

The Water (Fluoridation) Act 1985 placed the responsibility for decisions on water fluoridation with district health authorities, who are required to consult locally before making a formal request to the water undertaker. It was assumed, incorrectly as we now know, that water undertakers would concern themselves mainly with the technical feasibility of the proposal. ${ }^{8}$ Experience in the North Western Region, where 18 district health authorities completed consultation in 1988, and more recently in Strathclyde, Yorkshire, Wessex, and Northern Ireland, clearly shows that health authorities can obtain substantial public and professional support for fluoridation, even though opinion among local authorities remains divided. It is also clear that the cooperation of the water companies cannot be assumed.

For example, the chairman of Welsh Water stated recently that, in spite of assurances from the Drinking Water Inspectorate concerning the safety of fluoridation plant designed according to the Department of Environment's code of practice, ${ }^{6}$ his company would not continue fluoridation on Anglesey or extend fluoridation into the rest of Wales unless required to do so by the secretary of state. While ministers quite correctly point out that the act requires local consultation, it was surely not the intention of parliament that water undertakers should have such an absolute veto.

The recent fundamental review of dental remuneration by Sir Kenneth Bloomfield called for "a more robust approach" to fluoridation "which would not allow for indefinite procrastination in adopting measures judged by the competent health authorities to be both beneficial and cost effective." The secretary of state should now require water undertakers to implement fluoridation schemes when they are requested to do so by health authorities, subject to assurances that the proposed schemes are technically feasible and economically sensible.

MICHAEL A LENNON Professor of preventive dentistry

SHEILA C JONES

Research assistant

Department of Clinical Dental Sciences,

University of Liverpool,

Liverpool L69 3BX

1 Ministry of Health, Scottish Office, Minister of Housing and Local Government. The conduct of the fluoridation studies in the United Kingdom and the results achieved after five years. London: HMSO, 1962. (Reports on public health and medical subjects No 105.)

2 Department of Health and Social Security, Scottish Office, Ministry of Housing and Local Government. The fluoridation studies in the United Kingdom and the results achieved after eleven year. London: HMSO, 1969. (Reports on public health and medical subjects No 122.)

3 Thomas FD, Kassab JY. Fluoridation in Anglesey: a clinical study of dental caries in mothers at term. Br Dent f 1992;173:136-40.

4 Bickley SR, Lennon MA. Fluoride levels in water supplies in health districts in England and Wales. A survey conducted by the British Fluoridation Society in 1988. Community Dent Health 1989;6:403-13.

5 Jenkins GN. Recent changes in dental caries. BMF 1985;291:1297-8.

6 Department of the Environment. Code of practice on the technical aspects of fluoridation of water supplies. London: HMSO, 1987.

7 Department of Health. The health of the nation. London: HMSO, 1991:81-2.

8 Department of Health. Health service development: fluoridation of water supplies. London: Department of Health, 1987. ( $\mathrm{HC}(87) 18$.)

9 Bloomfield K. Fundamental review of dental remuneration. A report to the UK Health Ministers. London: Department of Health, 1992.

\title{
Urban slums and primary health care
}

\author{
The private doctor's role
}

Living in abject poverty and consulting a private doctor seem a contradiction, though not to slum dwellers in many developing countries. In some cities a relative plethora of doctors and rapid urbanisation have led to a boom in private medical practice, which now provides a substantial amount of curative care for the inhabitants, including the poor ( $p$ 673). ${ }^{1-3}$

At the same time as slum dwellers have been queuing to see their local private doctor, ideas from the political right have influenced the policy guidelines of international organisations with clout in developing countries. For example, the World Bank and the World Health Organisation now emphasise private options for health care delivery. ${ }^{45}$ This has led planners to focus on the substantial private sector already in existence in some countries. They want to know how this sector can be promoted, how the quality of care can be improved, and how private doctors can participate in national public health policies. ${ }^{67}$ Answers to these questions have important implications for slum dwellers, whose only local source of medical care may be private doctors.

The little that has been written about private health care in developing countries suggests great variations among doctors and countries. Excellent care is provided by some, but the general picture is depressing. In particular, it seems that the market forces that opened the doctors' doors in slums are determining the type and quality of the care that they provide.

Services are predominantly curative. Preventive health care, such as childhood immunisation and health promotion through advice on lifestyle, is uncommon. Consultations, mostly for minor ailments, are characteristically brief. The number of people seen is high-up to 100 patients a daythus ensuring that unit costs are kept low. Standard medical practice may be ignored, with excessive numbers of drugs or overly expensive formulations being prescribed. For example, in a study of 100 private doctors 80 treatment regimens for tuberculosis were identified. Only four of these followed the standard guidelines of WHO, and the prescribed regimens cost three times as much as the standard protocols. ${ }^{8}$ Some prescribing habits may adversely affect patients' health: systemic steroids for fever, psychotropic drugs for pain, and use of inappropriate antibiotics fall into this category. ${ }^{9}$ When it comes to referral anecdotal reports suggest that informal gratuities are being paid by specialists to doctors for referring patients, potentially leading to overinvestigation and overtreatment.

Have governments a responsibility for actively regulating the private sector? At the very least, they have an obligation to protect their populations from practices that may adversely 
affect their health. Beyond this the state may wish to encourage better quality service and extend the range of activities that private doctors provide to include preventive programmes such as immunisation. These goals seem reasonable on paper but require a strong political commitment to ensure the accessibility of basic primary health services to the population and the existence of a clear vision of the minimum level of service that the state expects.

Invoking state regulatory mechanisms to improve the quality of the service provided is likely to be complex. The process will be contingent on existing regulation in the countries, the opportunities that may arise, and the strength of opposition to change. Regulating doctors' qualifications, their premises, and the care they provide is clearly a starting point. Control may also be achieved through resource management, such as social insurance schemes or payment of retainers or fees for service. Professional development and postgraduate training in primary health care could be a useful adjunct in improving quality. A reliance on training, however, assumes that the poor service results from inadequate professional knowledge rather than the perversity of market forces.

Private doctors' response to stronger state regulation, especially in countries where the private sector is well established, is likely to vary. State activity that interferes with their autonomy is likely to be unpopular. Collaborative change, with negotiation between professional groups and the state, may be the best way forward, but without strong government control it risks becoming little more than a tinkering with the existing system. Ensuring that private practitioners take on preventive activities and promote healthy behaviour by their patients requires a substantial move away from a strictly market led approach. Incentives and fees for service will be needed to reduce private doctors' autonomy and increase their accountability to the state. Yet this requires state money for health care.

Clearly, substantial changes are needed rather than tinkering. The goal of donor led initiatives should be to improve health care, not to increase private provision. ${ }^{10}$ Ironically, the international political changes that shifted the focus to private practice were also inimical to regulation and state funding of health care. The time seems ripe to change these guiding beliefs.

PAUL GARNER

Lecturer

Department of Public Health and Policy,

London School of Hygiene and Tropical Medicine, London WC1E 7HT

Community Health Sciences Department,

Aga Khan University,

Karachi, Pakistan

1 Bennett S. Private care in Third World needs regulating. BMf 1993;306:673-4.

a Peters DH, Becker S. Quality of care assessment of public and private outpatient clinics in Metro Cebu, Philippines. Intemational fournal of Health Planning and Management 1991;6:273-86.

Bhat R. The private health care sector in India: some policy concerns. Harvard: Takemi Programme in International Health, 1991. (International research paper No 54 .)

Ward P. Reproduction of social inequality: access to health services in Mexico City. Health Policy and Planning 1987;2:44-57.

World Bank. Financing health services in developing countries: an agenda for reform. Washington, DC: World Bank, 1987

World Health Organisation. The public/private mix in nationalhealth systems and the role of ministries of health. Report on an interregional meeting. Geneva: WHO, 1991.

6 Green A. The role of non-governmental organizations and the private sector in the provision of health care in developing countries. International fournal of Health Planning and Management 1987;2:37-58.

7 Bennett S. Promoting the private sector: a review of developing country trends. Health Policy and Planning 1992;7:97-110.

8 Uplekar M. Implications of prescribing patterns of private doctors in the treatment of tuberculosis in Bombay, India. Harvard: Takemi Programme in International Health, 1989. (International research paper No 41 .)

9 Greenhalgh T. Drug prescription and self medication in India: an exploratory survey. Soc Sci Med 1987;25:307-18.

10 Bennett S. The mystique of markets: public and private health care in developing countries. London: Department of Public Health and Policy, London School of Hygiene and Tropical Medicine, 199
Not often are authors of $B M \mathcal{F}$ papers arrested by the fraud squad, but this is what happened to the authors of the paper on $\mathrm{p} 691$. $^{1}$ They sent matched pairs of simulated curriculum vitaes - one bearing an English name and one an Asian name-in response to 23 advertisements for senior house officer posts. The only important difference between the curriculum vitaes was in the name, and yet the English names were significantly more likely to be shortlisted than the Asian names. Although the authors were charged by the fraud squad, they were not prosecuted.

We must always question the use of deception in research, but in this case the public and professional importance of the question being asked seems to justify the small element of deception. Ideally, the authors might before beginning the study have gained informed consent from the personnel departments of all the hospitals likely to be approached. This method has been used to gain consent from general practitioners for research in which they are consulted by surrogate patients. There would, however, have been at least two problems with using this method in the present study. Firstly, everybody likely to be a member of a selection panel would have had to give consent-a formidable logistic problem. Secondly, even a small proportion of people declining to give consent might have undermined the study- if those declining included most of those who knew that they allowed race to influence their judgments when shortlisting candidates for jobs.

The second crucial question is whether these results could have been obtained without deception. An expanding body of work does provide evidence of racial discrimination in medicine, ${ }^{2-6}$ and St George's Hospital Medical School was found to be using a computer program to shortlist applicants that downgraded those with non-English names. ${ }^{7}$ Nevertheless, most of this work is retrospective and there were other variables apart from racial differences. The present study was prospective and allowed only race to vary-and so adds important information.

Much research does include some deception. A placebo controlled trial does not present this problem because subjects give informed consent, but regularly in case-control studies subjects are not told the true reason for the study for fear that the study will be biased. Stooges are used increasingly in research on how general practitioners and pharmacists perform, and some famous studies have depended on substantial deception. Our thinking on mental hospitals has been strongly influenced by studies in which researchers pretended to be mentally ill, and in a television programme broadcast last week in Britain a reporter pretended to be homeless and 